\title{
OPEM
}

www.opem.org

Oriental Pharmacy and Experimental Medicine 2010 10(2), 103-110

DOI 10.3742/OPEM.2010.10.2.103

\section{Seed extracts of a Bangladeshi medicinal plant Abrus precatorius L. show antifertility activity in female rats}

\author{
MA Hannan ${ }^{1, *}$, MA Hossain ${ }^{1}$ and MT Islam ${ }^{2}$ \\ ${ }^{I}$ Department of Biochemistry, Faculty of Agriculture, Bangladesh Agricultural University, Mymensingh-2202, \\ Bangladesh; ' Ecological Chemistry, School of Agriculture and Rural Development, Bangladesh Open University, \\ Gazipur, Bangladesh
}

Received for publication September 11, 2008; accepted March 25, 2010

\begin{abstract}
SUMMARY
The seed powder of Abrus precatorius L. has traditionally been used as oral contraceptive agent by the women in some rural areas in Bangladesh. The present study aimed to examine the antifertility activity of $A$. precatorius seed extracts in experimental female rats. Finely ground seeds were extracted with aqueous acetone followed by successive partitioning with $n$-hexane, ethyl acetate (EtOAc), methanol $(\mathrm{MeOH})$ and water. Water suspended crude seed powder, organic fractions of acetone extract and a standard contraceptive drug (Nordette ${ }^{\circledR} 28$ ) were separately administered orally to the female rats for 30 days. $n$-Hexane, EtOAc and $\mathrm{MeOH}$ solubles at the doses of 2, 4 and 6 $\mathrm{mg} / \mathrm{rat} /$ day, respectively and crude seed powder at $100 \mathrm{mg} / \mathrm{rat} /$ day exhibited $100 \%$ antifertility activity with lowest levels of serum luteinizing hormone (LH), follicle stimulating hormone (FSH) and $17 \beta$-estradiol. Histological study of ovary and uterus of these rats exhibited reduced number of developing follicles and increased number of atretic follicles in the ovary, and fewer uterine glands with shrunken morphology, reduced endometrial height, poor vascularity and compact stroma in uterus. However, the activities of serum glutamate oxaloacetate transaminase and serum glutamate pyruvate transaminase and the body weight of the rats remained almost unaffected in all the seed extract treated rats compared to control. These results suggest that $A$. precatorius seed extracts reduced the levels of serum $\mathrm{FSH}, \mathrm{LH}$ and $17 \beta$-estradiol probably by affecting hypothalamicpituitary-gonadal axis. The reduced levels of these hormones might have affected the oestrous cycle, follicular development, and subsequently the establishment of pregnancy in treated rats.
\end{abstract}

Key words: Abrus precatorius; Antifertility effect; Seed extracts; Gonadotropins; Female rat

\section{INTRODUCTION}

The use of plant materials for antifertility purposes has been known in traditional medicine worldwide. Abrus precatorius, popularly known as precatory

*Correspondence: MA Hannan, Department of Biochemistry, Faculty of Agriculture, Bangladesh Agricultural University, Mymensingh-2202, Bangladesh Tel.:+821055117835/ +8801719538440; Fax: +8809161510; Email: hannanbau @gmail.com bean, rosary pea or ratti, an endemic traditional medicinal plant, is such a plant whose powdered seeds are used by ayurvedic practitioners as oral contraceptive (Basu and Kirtikar, 1980; Ratnasooriya et al., 1991). The seeds of $A$. precatorius have many other medicinal uses. The seeds were used to treat diabetes (Akhidue and Monago, 2003; Alumanah and Monago, 2005), tetanus, chronic nephritis, laryngitis, hepatitis, bronchitis, scratches and sores, abscesses, wound caused by dogs, cats and mice, 
diarrhea (Alumanah and Nwodo, 1991), and also used with other ingredients to treat leucoderma. Powdered seed of A. precatorius functions against mange infestation (Dwivedi and Sharma, 1985). Various African tribes use powdered seeds as oral contraceptive (Breyer-Brandwijk and Watt, 1962). The goldsmiths have been using them from the very early time for weighing gold and silver. The boiled seeds of $A$. precatorius were taken by the residents of Andaman Island of India (Janardhanan and Rajaram, 1992).

It is known that a village homeopathic doctor in Brahmanbaria, Bangladesh is using A. precatorius seeds as an oral contraceptive agent. He uses crude seed powder to prepare small tablets (equivalent to 3 seeds/tablet) for the rural women. Interview with the doctor and the rural women using this natural drug revealed that it is an effective oral contraceptive product. Although the antifertility activities of $A$. precatorius seed extracts in male rats have been reported (Rao, 1987; Mathur and Sinha, 1990; Sinha, 1990), there is no documented evidence to support the same in case of female rats. A systematic study is needed to understand the contraceptive mechanism of $A$. precatorius seed powder in rural women. As a first step, it may be important to test the antifertility activity of $A$. precatorius seed extracts in female rats. Therefore, the objectives of the present study were to assess the comparative antifertility activity of different extracts and crude powder of $A$. precatorius seeds and to study the impact on reproductive parameters like hormonal profiles (LH, FSH and estrogen), main reproductive organs and on the vital organs. This report describes our preliminary findings on antifertility activity of different organic extracts of A. precatorius seeds in female rats.

\section{MATERIALS AND METHODS}

\section{Plant material}

Fresh pulverized seeds of $A$. precatorius L. were collected from a local homeopathic doctor in
Brahmanbaria, Bangladesh. Three hundred grams $(300 \mathrm{~g})$ of seed powder was used for extraction and $10 \mathrm{~g}$ was administered as crude powder. Rest of the amount was stored as reference materials in the Biochemistry laboratory.

\section{Extraction of seed samples}

Three hundred grams (300 g) of powdered seed sample was divided into three equal parts for the convenience of extraction. Each $100 \mathrm{~g}$ ground sample was treated with $60 \%$ aqueous acetone (500 $\mathrm{ml}$ ) in separatory funnel and allowed to stand for 3 days with occasional stirring at room temperature. After filtration, the residues were re-extracted twice with $500 \mathrm{ml}$ of $60 \%$ aqueous acetone and kept for two days with occasional stirring. All the filtrate portions were collectively mixed and concentrated under vacuo in rotary evaporator at a temperature not exceeding $40^{\circ} \mathrm{C}$. The concentrated slurry was subjected to freeze-drying. The residual portion after acetone extraction was subjected to further methanol extraction leading to aqueous extraction. The acetone extract was subjected to chemical partitioning with $n$-hexane, EtOAc, $\mathrm{MeOH}$ and water. $n$-Hexane, EtOAc, $\mathrm{MeOH}$ and water soluble materials were separately used for bioassay.

\section{Experimental animals}

Adult mixed albino rats (Long Evan's strain- 3 months old and $180 \pm 10 \mathrm{~g}$ in weight) both male and female were obtained from Laboratory Animal Division, International Center for Diarrhoeal Disease Research, Bangladesh (ICDDR,B), Dhaka. Upon arrival, the rats were acclimatized under standard laboratory conditions ( $12 \mathrm{~h}$ light: $12 \mathrm{~h}$ dark), and allowed to free access to feed (standard pellet diet) and water ad libitum throughout the tenure of experiment. Vaginal smears were checked daily to characterize the estrous cycle of animals. They were tested for their fertility. For this purpose, all female rats were caged with male (at the ratio of 2:1) and observed till parturition (up to 25 days). They were then separated and only fertile female 
rats were selected for experiment.

\section{Experimental design and treatment schedule}

Two sets of experiment were conducted in this study. The first set was designed to find out the effects of seed extract on serum levels of follicle stimulating hormone (FSH), luteinizing hormone (LH) and estradiol, body weight, histology of ovary and uterus, and the histoarchitecture of liver, kidney and pancreas, and the serum SGOT and SGPT activity; the second set of experiment was carried out to investigate the effects of the extract on fertility and pregnancy of female rats.

In each set of this study, the fertile female rats with four days estrous cycle were randomly divided into eleven groups, three animals each, a control group fed normal diet only, a positive control group treated with a proven contraceptive drug Nordette ${ }^{\circledR} 28(0.15 \mathrm{mg}$ levonorgestrel and 0.03 mg ethinyl estradiol per tablet- Wyeth-Pharma GmbH Munster, Germany) 1 pill/rat/day, and other nine groups treated with test materials: one of crude seed powder (100 mg/rat/day), two separate doses each of $n$-hexane solubles ( 2 and 4 $\mathrm{mg} / \mathrm{rat} /$ day respectively), ethyl acetate solubles (2 and $4 \mathrm{mg} / \mathrm{rat} /$ day respectively), methanol solubles ( 3 and $6 \mathrm{mg} / \mathrm{rat} /$ day respectively) and aqueous solubles (4 and $8 \mathrm{mg} / \mathrm{rat} /$ day respectively) daily for 30 days.

\section{Measurement of Body weight}

Body weight of rat from each group was taken after treatment at every 10 days interval.

\section{Administration of drug and test material}

Water suspended extracts of $A$. precatorius seeds as well as standard drug were administered orally to the rats with the help of micropipette.

\section{Collection of blood and tissue samples}

After the last oral dose in the first set of experiment, all the rats were waited for the onset of estrous phase and then their blood was collected directly from heart after mild ether anesthesia and finally they were sacrificed with decapitation. For histological study, ovary, uterus, liver, kidney and pancreas were collected from sacrificed rats.

Hormonal profiling and analysis of SGOT and SGPT activities of blood samples

Serum samples were separated from coagulated blood by centrifugation and stored at $-15^{\circ} \mathrm{C}$ until assayed for LH, FSH and estradiol by radioimmunoassay (RIA), and SGOT and SGPT activities. All the biochemical determinations were carried out with the help of analytical kits.

\section{Histological study}

The collected tissue samples were trimmed and placed in 10\% neutral buffered formalin, embedded in paraffin by routine method, serially sectioned and stained in hematoxylin/eosin.

\section{Activity of Abrus precatorius seed on fertility and pregnancy of female rats}

For fertility and pregnancy study in the second set of the experiment, control and treated female rats were caged with fertility proven males on the $20^{\text {th }}$ day of treatment. They were monitored till parturition (25 days after male inoculation).

\section{Statistical analysis}

All data were analyzed by Completely Randomized Design under one way analysis of variance, followed by Duncan's multiple range test, with least significant differences at $P<0.05$.

\section{RESULTS}

Effect of Abrus precatorius seed solubles on serum levels of FSH, LH and estrogen in female rats

The higher doses of methanol solubles, ethyl acetate solubles and lower dose of $n$-hexane solubles (at the doses of 6,4 and $2 \mathrm{mg} / \mathrm{rat} /$ day respectively) and crude powder (100 mg/rat/day) of $A$. precatorius seed, and standard drug in aqueous suspension 


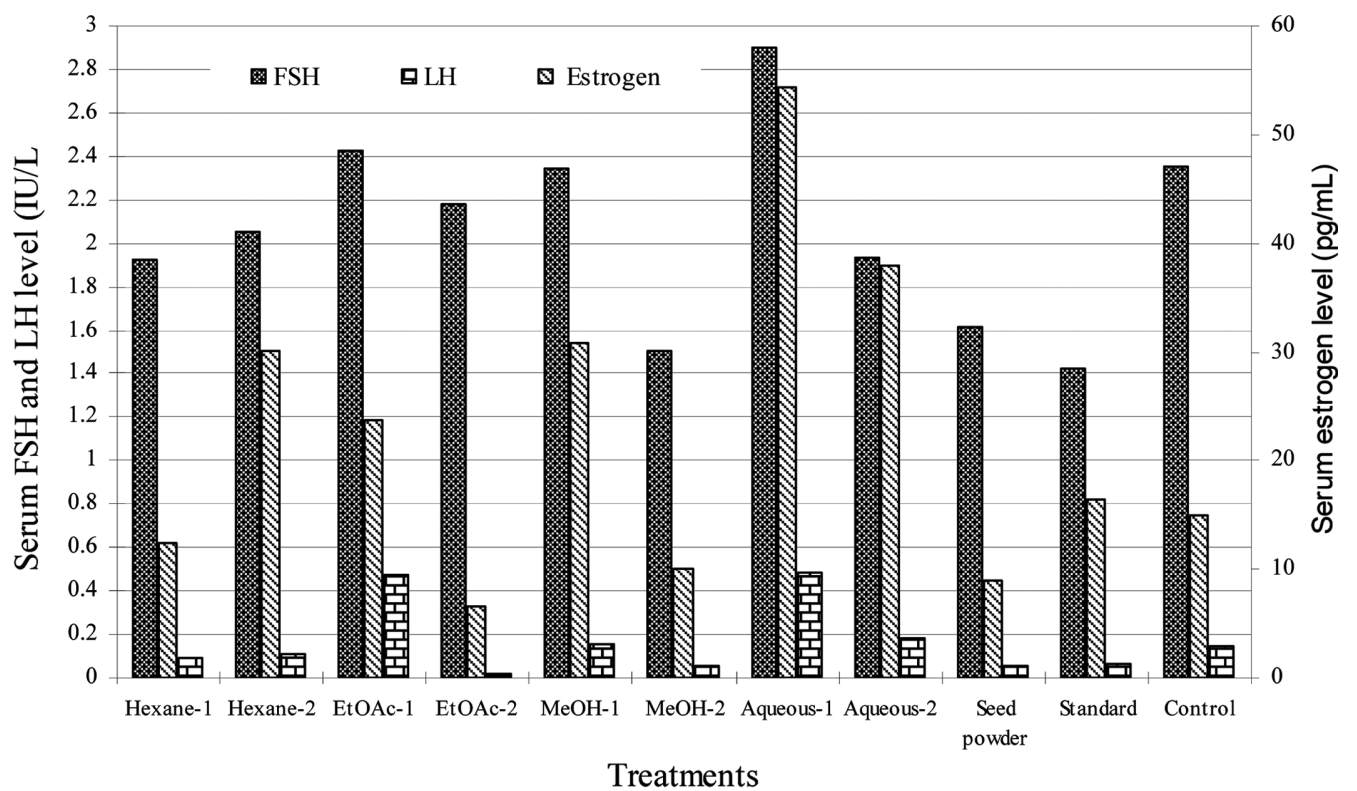

Fig. 1. Effect of Abrus precatorius seed soluble on serum level of FSH, LH and estrogen in female rats.

significantly reduced the levels of FSH, LH and estradiol in serum of treated rats compared to the control group (Fig. 1). However, other doses did not alter serum FSH and LH levels although curiously, estradiol level exceeded above normal in animals treated with the lower dose.

Effect on main reproductive organs (ovary and uterus) of female rats

Histological study of ovary revealed that treatment with methanol solubles, ethyl acetate solubles and $n$-hexane solubles at the doses of 6,4 , and $2 \mathrm{mg} /$ rat/day respectively and crude seed powder (100 $\mathrm{mg} / \mathrm{rat} /$ day) reduced the number of developing follicles and increased the number of atretic follicles in the ovary of treated rats compared to control (Fig. 2). Other doses did not cause remarkable change in the above organs.

Uterine histoarchitecture visualized that treatment with seed methanol solubles, ethyl acetate solubles, $n$-hexane solubles at the doses of 6,4 and $2 \mathrm{mg} /$ rat/day respectively and crude seed powder at 100 $\mathrm{mg} / \mathrm{rat} /$ day reduced endometrial height of the uterus. The uterine glands were fewer in number

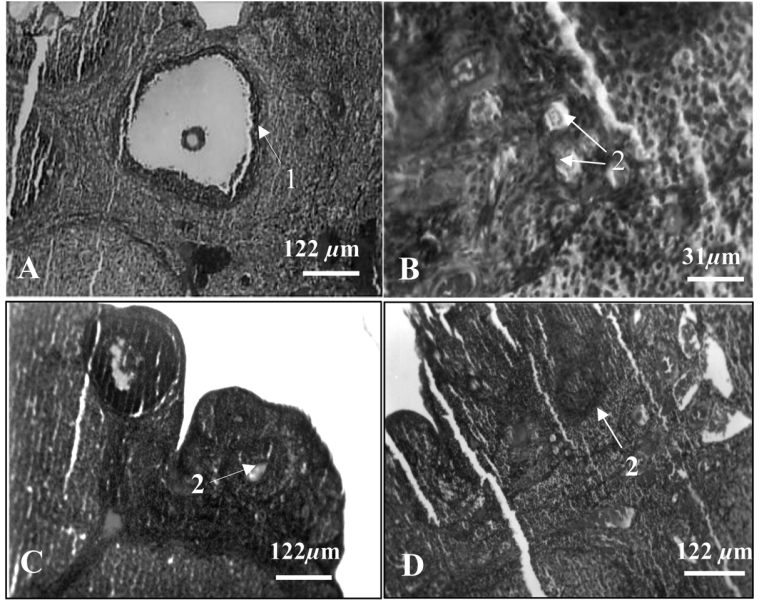

Fig. 2. Histology of ovary of rat. A, Section of ovary (control), showing fully matured follicle (1); B, C and $\mathrm{D}$, Sections of ovary (methanol solubles, ethyl acetate solubles, and $n$-hexane solubles treated, respectively), showing huge atretic follicles (2).

and had shrunken morphology. The vascularity was poor and stroma was compacted as compared to control (Fig. 3). Other doses did not cause remarkable change in the above mentioned organs. 


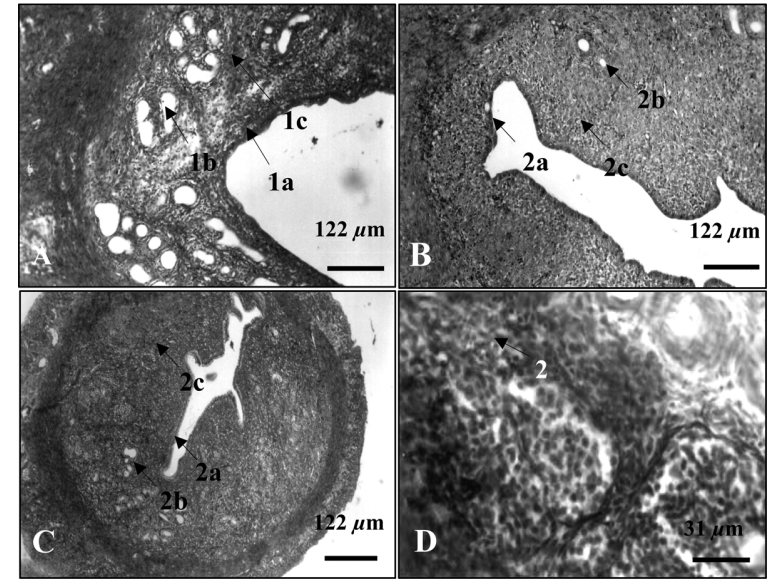

Fig. 3. Histology of uterus of rat. A, Section of uterus (control), showing normal endometrial height (1a) and profound development of uterine glands (1b) with rich vascularity (1c); B, C, D, sections of uterus (methanol solubles, $n$-hexane solubles, and ethyl acetate solubles treated, respectively), showing reduced endometrial height (2a), fewer uterine glands with shrunken morphology (2b) and poor vascularity (2c).

\section{Effect on other vital organs}

The histological pictures of liver, kidney and pancreas of treated rats were appeared to be normal compared to control (figure not shown).

Effects on serum enzymatic (SGPT and SGOT) activities

The graphical representation of the effects of $A$. precatorius seed extract on SGOT and SGPT activity showed that treated groups were at normal SGOT and SGPT activity with negligible variation compared to control group (Fig. 4).

\section{Effect on body weight}

There was no significant difference between the body weights of the control and treated animals.

Effect of Abrus precatorius seed solubles on fertility and pregnancy of female rats

$n$-Hexane solubles, ethyl acetate solubles and methanol solubles (at 2, 4 and $6 \mathrm{mg} / \mathrm{rat} /$ day) and crude seed powder $(100 \mathrm{mg} / \mathrm{rat} /$ day $)$ elicited maximum antifertility (Table 1).

\section{DISCUSSION}

In vivo bioassay using Abrus precatorius seeds in female rats revealed that $n$-hexane solubles ( 2 and $4 \mathrm{mg} / \mathrm{rat} /$ day), ethyl acetate solubles $(4 \mathrm{mg} / \mathrm{rat} /$ day) and methanol solubles (6 mg/rat/day) and crude seed powder $(100 \mathrm{mg} / \mathrm{rat} /$ day $)$ elicited antifertility activity and effectively blocked pregnancy of female rats. This is the first indication that $A$. precatorius seed powder contains secondary metabolites which are responsible for antifertility in female rats.

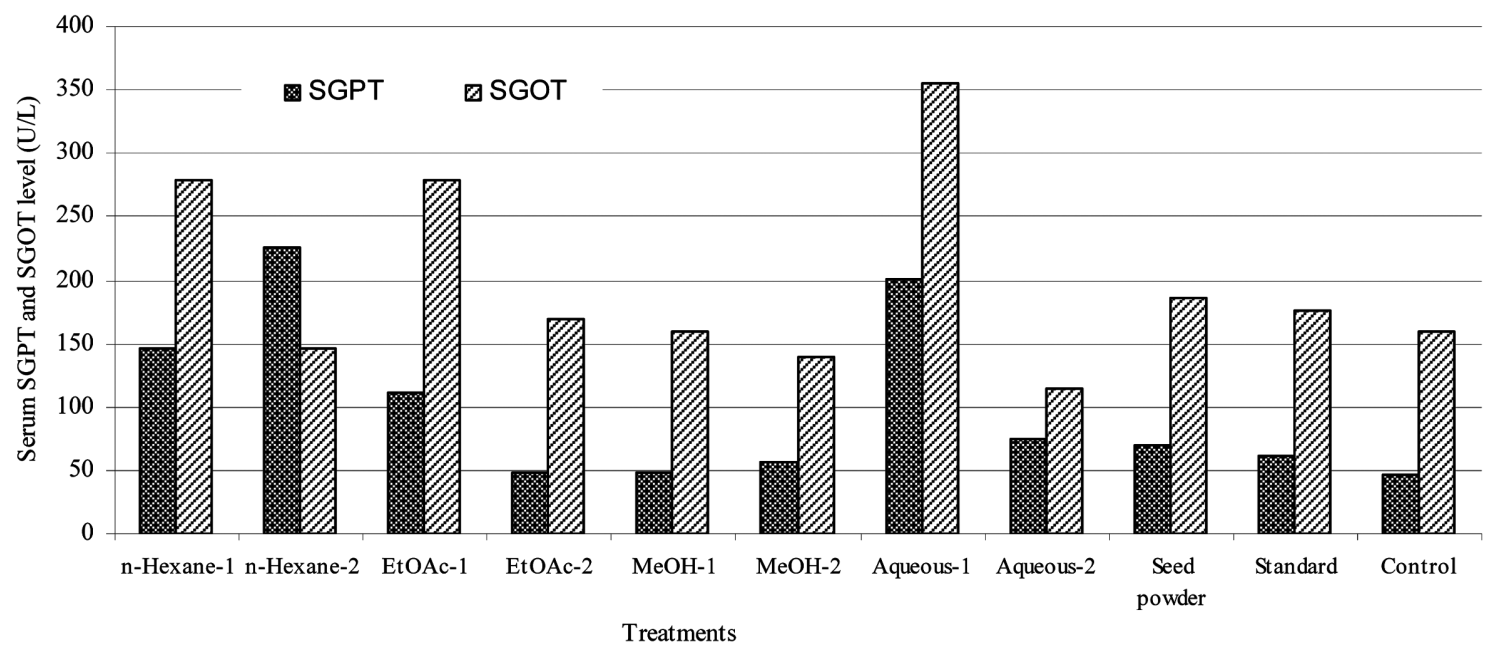

Fig. 4. Effect of Abrus precatorius seed soluble on serum SGPT and SGOT level in female rats. 
Table 1. Effect of $A$. precatorius seed extracts on fertility and pregnancy of female rats

\begin{tabular}{lccc}
\hline Treatment & Dose $(\mathrm{mg} / \mathrm{rat} /$ day) & Infertile mating $(\%)$ & No. of pregnant rats $(\%)$ \\
\hline$n$-Hexane solubles & 2 & 100 & 0 \\
Ethyl acetate solubles & 4 & 33.33 & 66.66 \\
& 2 & 0 & 100 \\
Methanol solubles & 4 & 100 & 0 \\
& 3 & 33.33 & 66.66 \\
Aqueous solubles & 6 & 100 & 0 \\
& 4 & 0 & 100 \\
Crude seed powder & 8 & 0 & 100 \\
Nordette $^{\circledR} 28$ & 100 & 100 & 0 \\
Control & 1 pill/rat/day & 100 & 0 \\
\hline
\end{tabular}

This result supports why it has long been used as natural female contraceptive by rural women in Indian Subcontinents including Bangladesh (Basu and Kirtikar, 1980). It appeared from this study that the active principle in seed extract is not a single compound because all organic fractions such as $n$-hexane, EtOAc and $\mathrm{MeOH}$ solubles displayed more or less antifertility activity in female rat. A further bioassay-guided chromatographic separation should lead to the isolation of the active principles from the seed extract.

Our hormonal analysis and histoarchitectural studies revealed that $A$. precatorius seed solubles significantly reduced the levels of $\mathrm{FSH}, \mathrm{LH}$ and estradiol in serum and caused reduction in the number of developing follicles and increased the number of atretic follicles in the ovary of treated rats compared to control.

The results supported a possibility of hypothalamic/ pituitary site of action of seed extract. This finding might be associated with subnormal levels of gonadotropins ( $\mathrm{LH}$ and $\mathrm{FSH}$ ) that might have reduced the number of developing follicles and increased the number of atretic follicles in the ovary, since gonadotropic hormones were directly or indirectly responsible for the growth and development of follicles. Atresia is the normal phenomenon by which the number of follicles degenerates during development and apoptosis is known to have a fundamental role in follicular atresia (Gorospe and Hughes; Tilly et al., 1991). But the present histological study revealed the presence of more atretic follicles in the ovary upon treatment with the above mentioned doses. Since gonadotropins were the regulator of follicular development (Nimrod et al., 1976; de Wolff-Exalto, 1982; Albertini and Wassarman, 1994) and steroid production in rats (Albertini and Wassarman, 1994), it was quite possible that subnormal levels of gonadotropins might have affected oocyte development and maturation, ovulation, and corpora lutea formation in rat (Terranova, 1981).

The pulsatile secretions of pituitary gonadotropins regulate steroidogenesis in the ovary. Estrogen is primarily responsible for the regulation of estrous cycle in lower animals (Terranova, 1981; Albertini and Wassarman, 1994). The modulation of estrous cycle may be due to the unavailability of estrogen at a required level in treated rats. To support this possibility, we analyzed estradiol level in the serum of control and treated rats. Our results have indicated that treatment with $n$-hexane solubles (2 and $4 \mathrm{mg} / \mathrm{rat} /$ day), ethyl acetate solubles $(4 \mathrm{mg} /$ rat/day) and methanol solubles $(6 \mathrm{mg} / \mathrm{rat} /$ day $)$ and crude seed powder $(100 \mathrm{mg} / \mathrm{rat} /$ day) reduced the serum level of estradiol in treated rats.

The above findings further strengthened by uterine histology which revealed that treatment 
with seed methanol solubles, ethyl acetate solubles, $n$-hexane solubles at the doses of 6,4 and $2 \mathrm{mg} /$ rat/day respectively and crude seed powder at 100 $\mathrm{mg} / \mathrm{rat} /$ day caused unfavorable uterine milieu i.e., reduced endometrial height, fewer uterine glands with shrunken morphology, poor vascularity, and stroma compactness for fetal implantation. These results suggested that higher dose of $A$. precatorius seed extract and crude seed powder inhibited LH and FSH production by affecting hypothalamic-pituitary axis and thereby the level of estradiol in serum of treated animals (Coutiferis and Strauss III, 1999). The subnormal level of estradiol might have been disturbed on the uterine development in treated rats.

The effect of A. precatorius seed extracts had no deleterious effect on the liver, kidney and pancreas. The extract did not alter serum SGOT and SGPT activity which further supported the histopathological study of above organs, mainly liver.

The results highlighted in the Table 1 stated that A. precatorius seed extracts induced infertile mating, inhibited pregnancy in treated animals. This is possibly due to impairment in folliculogenesis and ovulation, which are occurred by combined action of sufficient LH and FSH whose production was inhibited by treatment with $A$. precatorius seed extract. However, it is further possible that $A$. precatorius seed extract might have disturbed the preparation of uterus by inducing histological and biochemical modifications in such a way that the implantation of embryo was inhibited in treated rats (Thakur et al., 2005).

In conclusions, results presented here clearly suggest that $A$. precatorius seed extract and crude powder reduced serum levels of gonadotropins probably by affecting hypothalamic-pituitary axis. The reduced levels of FSH and LH might have affected steroidogenesis in the ovary. Thus, subnormal level of steroid hormones may be the cause of impaired follicular development, increased atretic follicles in the ovary and disturbance in the estrous cycle of A. precatorius seed-treated rats. This might have affected establishment and maintenance of pregnancy in treated animals.

Further studies on antifertility mode of action of A. precatorius seed extract and its effects on female rats are needed for considering its practical use as a naturally occurring oral contraceptive agent in women.

\section{REFERENCES}

de Wolff-Exalto EA. (1982) Influence of gonadotropins on early follicles cell development and early oocyte growth in immature rat. J. Reprod. Fertl. 66, 637-642.

DwivediSK, Sharma MC. (1985) Therapeutic evaluation of an indigenous drug formulation against scabies in pigs. Indian Journal of Veterinary Medicine. 5, 97100.

Hughes FM, Gorospe WC. (1991) Biochemical identification of apoptosis in granulosa cells: evidence for a potential mechanism underlying molecular atresia. Endocrinology. 129, 2415-2422.

Kirtikar KR, Basu BD. (1980) Indian Medicinal Plants, vol. I. $2^{\text {nd }}$ ed. pp. 763-767, Bishen Singh Mahendra Pal Singh, India.

Monago CC, Akhidue V. (2003) Antidiabetic effect of crude glycoside of $A$. precatorius in alloxan diabetic rabbits. Global Journal of Pure and Applied Sciences. 9, 35-38.

Monago CC, Alumanah EO. (2005) Antidiabetic effect of chloroform-methanol extract of A. precatorius Linn seed in alloxan diabetic rabbit. J. Appl. Sci. Environ. Mgt. 9, 85-88.

Nimrod A, Erickson GF, Ryan KJ. (1976) A specific receptor in granulosa cells: properties of binding in vitro. Endocrinology. 98, 56-64.

Nwodo OWC, Alumanah EO. (1991) Studies of A. precatorius seeds II: antidiarrhoeal activity. J. Ethnopharmacol. 31, 395-398.

Rajaram N, Janardhanan K. (1992) The chemical composition and nutritional potential of the tribal pulse, A. precatorius L. Plant Foods Hum. Nutr. 42, 285-290.

Ratnasooriya WD, Premakumara GA, Tillekeratne LM. (1991) Post-coital contraceptive activity of crude extracts of Sri Lankan marine red algae. Contraception. 50, 291-299.

Rao MV. (1987) Antifertility effects of alcoholic seed 
extract of A. precatorius Linn. in male albino rats. Acta Eur Fertil. 18, 217-220.

Sinha S, Mathur RS. (1990) Effect of steroidal fraction of seeds of A. precatorius Linn. on rat testis. Indian J. Exp. Biol. 28, 752-756.

Sinha R. (1990) Post-testicular antifertility effects of $A$. precatorius seed extract in albino rats. J. Ethnopharmacol. 28, 173-181.

Strauss III J, Coutiferis C. (1999) The endometrium and myometrium: resolution and dysfunction. In: Reproductive Endocrinology, Pathophysiology and Clinical Management, edited by Jen SSC, Jaffle RB, Barbieri RL, pp. 218-256, Saunders Co., USA.

Thakur SC, Thakur SS, Chaube SK and Singh SP. (2005) An etheral extract of kamala (Mallotus philippinensis Lam.) seed induces adverse effects on reproductive parameters of female rats. Reprod. Toxicol. 20, 149-156.

Tilly JL, Kowalski KI, Johnson AL, Hsueh AJW. (1991) Involvement of apoptosis in ovarian follicular atresia and post-ovulatory regression. Endocrinology. 129, 2799-2801.

Terranova PF. (1981) Steroidogenesis in experimentally induced atretic follicles of the hamster: estradiol to progesterone synthesis. Endocrinology. 108, 1885.

Wassarman PM, Albertini DF. (1994) The mamalian ovum. In: The Physiology of Reproduction, edited by Knobil E, Neill JD, vol. 1. $2^{\text {nd }}$ ed. pp. 79-122.

Watt JM, Breyer-Brandwijk MG. (1962) The medicinal and poisonous plants of Southern and Eastern Africa, 2nd ed. p.1063, Livingstone, London. 